\title{
A Review of the Role of Food Insecurity in Adherence to Care and Treatment Among Adult and Pediatric Populations Living with HIV and AIDS
}

\author{
Sera Young • Amanda C. Wheeler • \\ Sandra I. McCoy $\cdot$ Sheri D. Weiser
}

Published online: 11 July 2013

(C) Springer Science+Business Media New York 2013

\begin{abstract}
Adherence to antiretroviral therapy (ART) is critical for reducing HIV/AIDS morbidity and mortality. Food insecurity (FI) is emerging as an important barrier to adherence to care and treatment recommendations for people living with HIV (PLHIV), but this relationship has not been comprehensively examined. Therefore, we reviewed the literature to explore how FI may impact ART adherence, retention in medical care, and adherence to health care recommendations among PLHIV. We found data to support FI as a critical barrier to adherence to ART and to other health care recommendations among HIVinfected adults, HIV-infected pregnant women and their HIV-exposed infants, and child and adolescent populations of PLHIV. Associations between FI and ART non-adherence were seen in qualitative and quantitative studies. We identified a number of mechanisms to explain how food insecurity and ART non-adherence may be causally linked, including the exacerbation of hunger or ART side effects in the absence of adequate food and competing resource demands. Interventions that address FI may improve adherence to care and treatment recommendations for PLHIV.
\end{abstract}

S. Young $(\bowtie)$

Division of Nutritional Sciences, Cornell University,

113 Savage Hall, Ithaca, NY 14850, USA

e-mail: sera.young@cornell.edu

A. C. Wheeler · S. I. McCoy

Division of Epidemiology, University of California,

Berkeley, CA, USA

S. D. Weiser

Division of HIV/AIDS and Center for AIDS Prevention Studies, Department of Medicine, San Francisco General Hospital, University of California, San Francisco, CA, USA
Keywords HIV/AIDS · Food security · Pregnancy · Adults · Children · Adherence

\section{Introduction}

Adherence to antiretroviral therapy (ART) is critical for reducing HIV/AIDS morbidity and mortality. Indeed, ART non-adherence is the most consistent predictor of incomplete viral load suppression, development of drug resistance, and progression to AIDS and death [1-5]. Although ART has significant individual clinical benefits $[6,7]$ and substantially reduces sexual [8] and vertical transmission of HIV [9], these benefits hinge upon the timely detection of infection, rapid linkage to care, and high levels of adherence. Thus, identifying the many barriers to initiating and sustaining ART is critical to ensure its individual and public health benefits.

Food insecurity, when people do not have physical, social, and economic access to sufficient safe and nutritious foods that meet their dietary needs and food preferences for an active and healthy life [10], is emerging as an important barrier to adherence to care and treatment recommendations for people living with HIV and AIDS (PLHIV). To date, most research has examined associations between food insecurity and adherence to ART among the general adult HIV-infected population. However, burgeoning data also suggest that food insecurity may negatively impact adherence to care and treatment recommendations among specific sub-populations, such as HIV-infected pregnant women and their HIV-exposed infants as well as children and adolescents living with HIV infection.

Thus, the purpose of this paper is to provide an overview of the relationship between food insecurity and adherence 
to HIV care and treatment recommendations for PLHIV, and to review the evidence on potential pathways by which food insecurity may adversely impact adherence to HIV care recommendations among three distinct populations: (1) general adult populations of PLHIV, (2) HIV-infected pregnant women and their HIV-exposed infants, and (3) child and adolescent populations of PLHIV.

\section{Methods}

We conducted a narrative review of the state of the evidence on food insecurity and ART adherence. We identified key articles in the qualitative and quantitative literature that illustrate current findings on this relationship. We searched PubMed and Google Scholar using key words such as "food security," "food insecurity," "adherence," "compliance," "HIV," "AIDS," and "nutrition" to identify relevant literature. Relevant English language articles were reviewed for possible inclusion. We also identified sources from the bibliographies of included papers and conference presentations related to food insecurity and adherence to treatment and care.

\section{Results}

\section{Overview of Barriers to Adherence Among PLHIV}

"Adherence" encompasses the entire spectrum of activities required to preserve the health of PLHIV, including early testing, retention in care, and initiation and continuation of ART [11, 12]. There are a number of comprehensive models for understanding healthcare utilization and adherence, described elsewhere [11, 13-15]. These models often describe barriers to adherence to HIV care and treatment recommendations as operating at the individual, household, institutional, or structural levels (summarized in Table 1, stratified by dimension within each level) $[11,16$, 17]. Food insecurity, while usually assessed at the household level, has negative health impacts at the individual level and is strongly linked with structural factors at the community level (such as food availability and prices).

Individual-level barriers include patient-related characteristics, such as fear of disclosure [18-20, 53] concurrent mental illness and addiction [24, 54, 55], denial of HIV diagnosis or other health beliefs [28-30], level of trust in providers [28, 30, 56], and distance and transportation costs to and from clinics [18, 20, 31, 34]. In addition, regimenrelated factors influence adherence at the individual level including medication side effects, regimen characteristics, and dosing schedule [27, 35-37, 53, 57].
At the household level, besides food insecurity, interpersonal relationships with partners or family members can also influence the decisions to seek HIV testing, engage in care, and stay in care. Lack of support from family or friends has been found to be a significant risk factor for non-adherence to ART [19, 26, 28, 53]. Unstable housing [25, 43] and other financial constraints [35, 24, 19, 26, 44] are other important household-level barriers. There is strong evidence that women in poorer households access health services, such as antenatal care, less frequently than women in households that are better off [58, 59]. This is critical given that a large proportion of women do not know their HIV status when they become pregnant, and accessing health care is requisite for being tested. Pressure to share medications is another household factor known to negatively impact adherence to ART [38].

At the institutional level, distance to the facility [18, 35], heavy staff workloads [18, 46], long waiting times [18, 20, 29], and high user fees [18] have been identified as challenges to adherence to ART and retention in HIV care. At the community level, structural barriers to adherence to ART include HIV-related stigma and discrimination [18, $24,35]$, gender inequalities [48, 60], weak food or agricultural systems [49], political or economic crises [50-52] and poverty and poor living conditions [19, 61, 62].

Many of these barriers and facilitators to adherence to ART are universally important and relevant in both resource-rich and resource-poor countries. However, they often manifest differently in different settings. For example, in resource-poor countries, poverty itself may inhibit the ability to obtain treatment through prohibitive healthcare-associated costs, while in resource-rich countries it may be the correlates of poverty such as addiction or depression that prevent PLHIV from obtaining adequate care or adhering to medications [4].

Adherence to ART among pediatric populations has additional challenges across all these levels, as it is the product of the combined influences of child, caregiver, and household characteristics, medication regimen (e.g. pill size, availability of pediatric dosing), and features of the community and culture [63-65]. Pediatric adherence is also often complicated by the fact that many HIV-infected children have not been told of their diagnosis and do not understand why they must take medications [66]. Disclosure of HIV status to the child and to others may have both positive and negative implications for adherence to ART, as disclosure to the child influences the child's own motivation and willingness to take medications, whereas disclosure to others has the potential to affect social support, stigma, and/or discrimination at school or in the community, which could potentially negatively affect adherence [64, 66, 67]. 
Table 1 Factors influencing ART adherence among HIV-infected adults

\begin{tabular}{|c|c|c|}
\hline Level & Factors & Examples, by Country \\
\hline \multirow[t]{9}{*}{ Individual } & Fear of disclosure & Botswana, Tanzania [18]; Kenya [19]; Uganda [18, 20] \\
\hline & Mental health & United States [21, 22]; Zambia [23] \\
\hline & Alcohol or drug use & Cameroon [24]; Canada [25]; South Africa [26]; United States [27] \\
\hline & Health beliefs & Botswana [28]; South Africa [29]; Tanzania [30]; Zambia [23] \\
\hline & Level of trust in providers & $\begin{array}{l}\text { Botswana [28]; Nigeria, Uganda [31]; Tanzania [30, 31]; United } \\
\text { States [32] }\end{array}$ \\
\hline & Distance to clinic/transportation costs & $\begin{array}{l}\text { Botswana [18]; Nigeria [31]; South Africa [17]; Tanzania [18, 31, 33]; } \\
\text { Uganda }[18,20,31,34]\end{array}$ \\
\hline & Side effects & Botswana [35]; Italy [36]; South Africa [29]; United States [32] \\
\hline & Regimen factors (e.g. complexity of dosing) & United States [27, 37] \\
\hline & Incorporating treatment into daily schedules & Tanzania [30]; United States [32]; Zambia [38] \\
\hline \multirow[t]{6}{*}{ Household } & Food insecurity & $\begin{array}{l}\text { Canada [39]; France [40]; Kenya [81]; Peru [41]; Rwanda [85]; South } \\
\text { Africa [17, 48]; Uganda [80]; United States [42] }\end{array}$ \\
\hline & Family and partner relationships & Cameroon [24]; South Africa [26]; United States [32]; Zambia [23] \\
\hline & Social support & Botswana [28]; Nigeria, Tanzania, Uganda [31]; United States [21] \\
\hline & Unstable housing & Canada [25]; United States [43] \\
\hline & Financial difficulties & $\begin{array}{l}\text { Botswana [35]; Cameroon [24]; Kenya [19]; South Africa [26]; } \\
\text { Uganda [44], United States [45] }\end{array}$ \\
\hline & Pressure to share medications & Zambia [38] \\
\hline \multirow[t]{5}{*}{ Institutional } & Long waiting times & Botswana, Tanzania [18]; Uganda [18, 20]; South Africa [29] \\
\hline & High user fees & Botswana, Tanzania, Uganda [18] \\
\hline & Heavy workloads of healthcare staff & Mozambique [46]; Tanzania, Uganda [18] \\
\hline & Poor counseling & Cameroon [24] \\
\hline & Medication stock-outs & Cameroon [24] \\
\hline \multirow[t]{4}{*}{ Community } & Stigma and discrimination & $\begin{array}{l}\text { Botswana [35]; Lesotho, Malawi, Swaziland, Tanzania [47]; South } \\
\text { Africa [17, 26, 47]; Uganda [20]; Zambia [23] }\end{array}$ \\
\hline & Gender inequalities & South Africa [48] \\
\hline & Weak food or agricultural systems & Kenya [49] \\
\hline & Political crises & Kenya [50-52] \\
\hline
\end{tabular}

Vicious Cycle of Food Insecurity and HIV

Food insecurity and HIV are "syndemic": there is a positive biological and social interaction in which one exacerbates the negative health effects of the other [68]. It is increasingly recognized that food insecurity both heightens vulnerability to HIV infection and at the same time exacerbates poor clinical outcomes among PLHIV [69-72]. Among PLHIV, food insecurity has been associated with incomplete HIV RNA suppression [73, 74], CD4 decline over time [75], lower body mass index [76], reduced quality of life, increased opportunistic infections, increased hospitalizations [77], and HIV-related mortality [71], often even after controlling for other markers of socio-economic status (SES). Advanced HIV-related illness further undermines income generation and food access, perpetuating a devastating cycle in which food insecurity is both a cause and consequence of deleterious health outcomes [78]. It is important to recognize that although food insecurity is highly correlated with poverty, the two are not synonymous, e.g. a household may have few assets but ample food. Indeed, studies have shown that food insecurity is associated with worse HIV health outcomes and ART nonadherence even after adjustment for SES [77, 79, 40, 42].

Food Insecurity and Adherence to ART Among Three Populations

\section{HIV-Infected Adults}

The possibility that food insecurity could negatively impact adherence among PLHIV was initially described in qualitative studies from low-resource settings in South America and sub-Saharan Africa. For example, a study among Ugandan individuals initiating ART found that lack of 
access to food was a key contributor to ART non-adherence and treatment interruptions among individuals on ART, and a barrier to ART initiation among those who had not yet initiated therapy [80]. South African health care providers [17] and PLHIV in South Africa [48] and Kenya [81] also reported food insecurity as one of the most important barriers to ART adherence. In Peru, respondents noted difficulties posed by nutritional requirements and being able to find enough food as barriers to ART adherence [82]. Studies have also shown that food insecurity negatively impacts adherence to treatment for other chronic diseases, such as tuberculosis [83].

Qualitative studies have highlighted four primary mechanisms by which food insecurity impedes adherence to ART in the general adult population of PLHIV (Table 2): (1) Fears or actual experiences of increased hunger on ART when people have to take ART on an empty stomach; (2) Fears or actual experiences of exacerbated side effects of ART in the absence of adequate nutritional intake; (3) The need to make trade offs between getting food or getting medicines leading people to sell or trade medicines for food or other resources; and (4) The need to make trade offs between paying for food and other medical care (including transport costs to clinic) leading to poor retention in medical care.

Intractable hunger with ART has been reported in qualitative studies from a number of African countries, where it has been perceived to be a strong contributor to ART nonadherence [18, 48, 80, 84]. For example, in a questionnaire administered to $71 \mathrm{HIV}$ patients in Rwanda, $76 \%$ participants indicated that "having too much appetite and not enough to eat" reduced adherence [85]. Similarly, in rural Uganda, HIV-infected participants described defaulting from treatment when food was scarce because they could not tolerate the increased hunger they experienced on ART. In addition, some individuals were reluctant to initiate ART in the first place, for fear of experiencing hunger without access to an adequate diet [80]. Increased hunger on ART has been hypothesized to be related to improved appetite after immunologic recovery and decreases in circulating cytokines [86-88].

Adverse side effects of ART taken without food, such as nausea, vomiting and stomach pain, are a second mechanistic link to poor adherence $[4,36]$. In qualitative studies in subSaharan Africa, PLHIV have complained that taking pills on an empty stomach led to headaches, stomach pain, dizziness, shivers or tremors, loss of energy, fainting, sweating, and rapid heartbeat [48, 80, 84]. This mechanism of worsened ART side effects in the absence of food contributing to ART non-adherence has been reported in a variety of settings including Uganda, Mozambique, and Kenya [80, 81, 89].

A third mechanism is that in the face of limited resources, demands for food may compete with resources needed to procure medicines. Even when clinic consultations are "free," clinical care is not without costs. These include opportunity costs, such as income foregone while traveling far distances to clinics or waiting in long lines for care, as well as expenditures required to receive care, such as payment for transportation to health care facilities. In many settings PLHIV struggle to simultaneously afford food, household expenses (e.g. rent, school tuition), medications, healthcare fees, and transportation costs to the clinic [44, 80, 90]. These competing demands sometimes contribute to trading or selling ART for food or other resources, further compounding problems with adherence. While these mechanisms have not been as well characterized in resource-rich settings, HIV often affects the poorest and most marginalized populations in those settings who face similar competing demands [25, 91, 92].

\section{Quantitative Studies}

A number of quantitative studies in resource-rich and -poor settings have substantiated these qualitative findings of an association between food insecurity and non-adherence. For example, in a cross-sectional study among 2,353 HIV-

Table 2 Overview of mechanisms for how food insecurity may contribute to non-adherence

\begin{tabular}{ll}
\hline Type of non-adherence & Mechanisms \\
\hline ART non-adherence & $\begin{array}{l}\text { Fear or actual experience of greater hunger on ART without access to an adequate diet } \\
\text { Fear or actual experience of side effects on ART that are exacerbated in absence of food } \\
\text { Competing resource demands e.g. food, leads medicines to be sold or traded } \\
\text { Competing resource demands prevent individuals from travel to clinic because of time or financial } \\
\text { constraints }\end{array}$ \\
$\begin{array}{l}\text { Poor retention in medical care } \\
\begin{array}{l}\text { Pon-adherence to recommendations } \\
\text { context of HIV }\end{array}\end{array}$ & $\begin{array}{l}\text { Competing economic activities prevent mother from being with child to breastfeed per } \\
\text { recommendations }\end{array}$ \\
\end{tabular}


infected US veterans, the proportion of those experiencing food insecurity (assessed using the validated Household Food Insecurity Access Scale) increased as adherence, measured by the proportion of time off of ART, decreased [74]. Among a cross-sectional sample of 457 HIV-infected individuals receiving highly active antiretroviral therapy (HAART) in British Columbia, Canada, $71 \%$ were food insecure (using a modified version of the validated Radimer/Cornell Questionnaire), and in unadjusted analyses there was an association between food insecurity and selfreported sub-optimal ART adherence, lower CD4 cell counts, and higher HIV viral loads [39]. In a national crosssectional survey of 1,809 HIV-infected patients in France, food privation in the household (defined as inability to afford at least one daily meal due to lack of money during the previous 4 weeks, indicated by a single-question response) was significantly associated with increased odds of self-reported ART non-adherence among 613 HIVinfected heterosexual men, but not among heterosexual women $(n=408)$ after adjustment for the financial situation of the household and other covariates [40]. In a crosssectional study that measured adherence with telephonebased unannounced pill counts among a convenience sample of $268 \mathrm{HIV}$-infected men and $76 \mathrm{HIV}$-infected women in Atlanta, food-insecure respondents (per an adapted version of the US Food Security Scale) had substantially reduced odds of ART adherence (defined as taking at least either 80 or $90 \%$ of medications) after controlling for SES-related factors such as education, unemployment, and income [42]. Food insecurity was also associated with barriers to HIV care and treatment, such as unstable housing, lack of transportation, substance abuse, and lack of social support [42].

Fewer quantitative studies have examined the relationship between food insecurity and adherence to ART in resourcepoor countries. In a longitudinal study among $134 \mathrm{HIV}$ infected adults in urban Peru, food insufficiency (defined as lack of enough food in the household in the previous month, according to a single question assessment) was significantly associated with a twofold increase in the odds of suboptimal adherence to ART. Associations held after adjusting for adherence self-efficacy, social support and other confounders, and there was a positive linear relationship between increasing frequency of food insufficiency (never, sometimes, often, almost always) and suboptimal adherence [41]. Inclusion of SES indicators (i.e. low education, unemployment, lack of basic services) in the analysis did not change the effect estimate by $>10 \%$ in either direction and was therefore not included in the final multivariate model [41].

A prospective cohort study of 488 HIV patients in rural Zambia indicated that baseline food insecurity was a strong predictor of sub-optimal ART adherence in unadjusted analyses, but when adjusted for factors such as wealth, the effect disappeared [93]. Importantly, they did not use a validated measure of food insecurity, and defined food insecurity as a lower number of meals taken during the "hunger season" than during most of the year, which is likely true for many poor families, even those who are food secure.

In addition to interfering with ART adherence, some data suggests that food insecurity may negatively impact adherence to clinic visits. For example, in a cohort of $458 \mathrm{HIV}$ infected ART-treated individuals in rural Uganda, mild and moderate food insecurity (assessed by the Household Food Insecurity Access Scale) were associated with missed clinic visits after adjusting for clinical, behavioral and SES confounders. Interestingly, in models where explanatory variables were lagged by 3 months relative to outcomes, severe food insecurity was associated with fewer missed clinic visits [77]. The authors explain that accessing outpatient care is a product of both need for care and means to get care when needed; it is therefore possible that individuals who were severely food secure were less likely to miss outpatient clinic appointments over the long run because they were sicker, and had higher need for care.

Food-related interventions have the potential to interrupt the various pathways through which food insecurity reduces adherence to ART and undermines the health of HIVinfected individuals [16]. Several intervention studies have shown positive impacts of food supplementation on HIV clinical outcomes, adherence to ART, and other treatment recommendations. For example, food supplementation programs in Zambia and Haiti demonstrated that food assistance improves a range of clinical outcomes, including adherence to ART [94-97].

\section{HIV-Infected Pregnant Women and their HIV-Exposed Infants}

Pregnant women are more likely to experience greater food insecurity than non-pregnant women because they have greater nutrient demands, less physical ability to obtain and prepare food, and less ability to engage in income-generating labor [98]. Limitations on their movement or physical activity may also be culturally proscribed, further exacerbating food insecurity. Strikingly, there are very few data on how food insecurity negatively impacts adherence to ART and other care recommendations among pregnant women [99]. Yet this population warrants particular attention because non-adherence has implications not only for a woman's health, but also for the health of her children, including the risk of vertical transmission of HIV. Increased food insecurity experienced by pregnant HIVinfected women may impact maternal health and infant care behaviors, including adherence to ART as well as to other healthcare recommendations, e.g. gestational weight gain and breastfeeding practices (Table 2). 
Antenatal and postnatal clinical care is critical for preserving the health of HIV-infected women and their infants [100] and antenatal clinic attendance increases the likelihood of clinic-based delivery, a recommendation for HIV-infected mothers [101]. Although care for HIV-infected pregnant women is provided free-of-charge in most parts of the world, food insecurity may impede the receipt of clinical care, as it does in the general HIV-infected adult population, by mechanisms previously discussed. Studies are needed to understand the impacts of food insecurity on access to and retention in antenatal and postnatal care, and whether the effects of food insecurity are distinct from the effects of low SES.

The 2010 WHO guidelines recommend the use of ART prophylaxis during pregnancy for all women, including those who are not eligible for ART for their own health, to reduce the risk of vertical transmission [102], and cotrimoxazole to reduce the risk of chorioamnionitis, prematurity and neonatal mortality [103, 104]. Further, the administration of ART prophylaxis during birth and in the early postpartum period has been demonstrated to reduce the risk of vertical transmission; as such, daily nevirapine or zidovudine in early life is recommended per international guidelines [105]. However, because clinics are the primary source for these medications, and most of these medications are dispensed to women in quantities sufficient for only 1 or 2 months, sporadic antenatal care due to competing resource demands for food can result in an irregular supply of medicines, which impedes sustained adherence to ART [101]. The existence of this relationship should be investigated empirically.

Adequate gestational weight gain is one of the most important modifiable predictors of birth outcomes [106]. Among pregnant HIV-infected women, wasting and low weight gain during pregnancy have been associated with increased mother-to-child transmission [107, 108] and increased risk of pre-term delivery and low birth weight [109]. It is recommended that HIV-infected women gain between 0.3 and $0.5 \mathrm{~kg}$ per week [110], yet pregnant women who are food insecure likely have less access to both desired quantities and quality of foods. This is particularly problematic during gestation, a time when most women become more selective about food intake because of nausea and vomiting [111], as they simultaneously need to increase their macronutrient and micronutrient intake. For these reasons, data on how food insecurity impacts gestational weight gain among HIV-infected women are needed.

In terms of safe infant feeding, the 2010 WHO recommendations encourage exclusive breastfeeding (EBF) for the first 6 months of life, even in the absence of ART, unless "environmental and social circumstances are safe for, and supportive of, replacement feeding" [112]. This is based on data showing a greatly elevated risk of vertical transmission associated with mixed feeding (breastfeeding and feeding other foods in the first 6 months of life) compared to EBF for 6 months as well as lower non-HIV morbidity and mortality rates observed among HIVexposed, exclusively breastfed infants compared to their mixed fed counterparts [113]. However, there is some evidence that mothers experiencing food insecurity feel unable to produce enough breastmilk to exclusively breastfeed for 6 months. In Malawi, for example, women of indeterminate HIV-status experiencing food insecurity felt that their breastmilk production was inadequate and were more likely to supplement their infant with nonbreastmilk foods prior to 6 months of age [114]. Similarly, Kenyan [115] and Ugandan [116] HIV-infected mothers experiencing food insecurity felt they were unable to exclusively breastfeed for 6 months. Even when mothers feel able to produce sufficient milk, food procurement activities may necessitate early separation from babywhich can also lead to early mixed feeding, or breastfeeding for shorter time than the 12 months minimally recommended in 2010 by the WHO. It is likely that food insecurity also prohibits a mother's ability to provide adequate nutrition to her children after the weaning period, further exacerbating the negative impacts of food insecurity, but this has not been explicitly evaluated in studies.

In summary, there are numerous ways that food insecurity may impact the ability of caregivers to adhere to recommendations to improve maternal health and reduce vertical transmission among HIV-exposed infants. Yet, there remains a striking dearth of actual data on the relationship of food insecurity to adherence to care and treatment recommendations among pregnant women and their infants. This area would benefit from both longitudinal observational studies as well as intervention studies to see if the mitigation of food security improves women's ability to adhere to guidelines for the care of herself and her HIV-exposed infants.

\section{Pediatric Populations}

Since HIV-infected children are reliant on caregivers for both medication and daily meals, children may be especially vulnerable to the potential for food insecurity and other resource constraints to impede adherence to ART. Indeed, food insecurity has now been cited as an important barrier to ART adherence among HIV-infected children in a number of studies in sub-Saharan Africa [63, 66, 67, 117].

Many of the mechanisms for how food insecurity negatively impacts adherence among children are similar to those described above among adults. However, an important difference is that among pediatric populations, one needs to consider both factors that affect children's adherence directly as well as factors that impede the ability of caretakers to provide care that supports adherence; this may be strongly related to the age of the child. For 
example, younger children are more reliant on the capacity of caregivers to procure and administer medications, whereas older children may face difficulties in managing treatment around school schedules and concerns about confidentiality [63].

Caregivers in Western Kenya reported that lack of sufficient food posed a challenge to pediatric ART adherence because of the belief that the medicine was too strong to be taken without food or that food was required to mitigate side effects [63]. In Democratic Republic of the Congo, HIVinfected children 8-17 years old similarly reported that side effects were alleviated through food consumption and that they would refuse to take their medicine if there was no food available [67]. The fact that some caregivers are elderly poses some new barriers to adherence not seen among the general adult population of PLHIV. For example, in Zimbabwe, immobility and the inability to work threatens the ability of elderly caregivers to secure enough food and maintain adequate ART for the children in their care [117].

The benefit of food supplementation on adherence has also been observed among children. A food supplementation intervention at a pediatric HIV/AIDS clinic in eastern India improved clinic visit adherence, CD4 counts, and reduced hospitalizations and deaths [118]. Further research is needed to understand the interplay between food insecurity, adherence to ART, and adherence to general care recommendations among HIV-infected children and the extent to which addressing food insecurity among children and their caregivers may contribute to improved pediatric adherence.

\section{Way Forward}

The research reviewed provides evidence of strong associations between food insecurity and poor adherence to care and treatment recommendations, and suggests plausible causal mechanisms (Table 2). However, there is a dearth of evidence from well-conducted longitudinal studies or experimental or quasi-experimental trials of interventions to confirm these findings and proposed mechanisms and to guide the development of initiatives in this area [119]. Particularly lacking are rigorous studies on the pathways by which food insecurity may impact adherence among vulnerable sub-populations, specifically, pregnant and lactating women and children.

Qualitative studies focusing on barriers to HIV care and treatment have been instrumental for hypothesis generation and understanding the complex interplay between food insecurity and adherence. In terms of quantitative work, nearly all published epidemiologic studies of food insecurity and ART adherence have been cross-sectional, which limits conclusions about causality. In addition, variability in the definitions and measurements of food insecurity, SES and adherence in these studies has limited comparisons of findings across settings. Furthermore, there is still little evidence on whether food insecurity interferes with adherence to other health recommendations beyond ART among adult and pediatric populations. Ultimately, data from rigorous longitudinal studies are needed to guide the development of interventions for PLHIV, especially during the first 6-12 months after ART initiation [77]. Data from both rigorously evaluated programmatic settings and randomized controlled trials will help to confirm and further refine the postulated causal mechanisms behind poor adherence to ART and thus suggest the most potentially efficacious interventions.

The few studies of the effects of food supplementation on HIV outcomes, including adherence (discussed above), suggest that food supplementation may be a promising approach to improving ART adherence. Nevertheless, there are many unanswered questions surrounding the role of food supplementation both in reducing food insecurity and improving adherence. These include: (1) whether food assistance should be used as an essential emergency intervention for malnutrition or as a longer-term approach to improve response to ART; (2) whether reducing food insecurity actually increases adherence to ART and to other health recommendations; (3) what types of food packages should be used for supplementation (and this will likely differ by country and context); and (4) what the optimal duration of food supplementation is. While food supplementation provides critical nutritional support, it may not fully address all facets of food insecurity (e.g., anxiety about stability of food supplies), and can perpetuate dependency on food aid [94, 95, 120].

Livelihood interventions that aim to sustainably increase food security may be more likely to achieve long-term improvements in adherence to ART. Livelihood intervention strategies typically integrate HIV care with income-generating programs, supporting clients in small-enterprise activities, agricultural production, or animal husbandry [49, 78, 121-124]. These interventions address numerous upstream pathways through which food insecurity negatively impacts health and thus show promise for having positive impacts on HIV/AIDS prevention, care and treatment.

\section{Conclusion}

In summary, more than 15 years after the HAART era began, the clinical efficacy of HIV care has never been greater. However, obstacles to adherence continue to undermine both the individual and public health benefits of widespread access to ART. Food insecurity is emerging as one such prominent barrier to ART adherence and to care and treatment recommendations in both resource-rich and poor settings, and among adult and pediatric populations. While this review has demonstrated that there are clear 
associations between food insecurity and poor adherence to HIV care recommendations as well as plausible mechanisms that can explain these correlations, more rigorous evidence is needed from longitudinal studies to determine whether these associations are indeed causal. Additionally, intervention studies are needed to evaluate the mechanisms and extent to which improving food security may lead to improvements in adherence to treatment and care recommendations. Evaluating the effectiveness, sustainability, and cost-effectiveness of various interventions to mitigate food insecurity, thereby improving adherence, will likely maximize the enormous potential impact of ART.

Acknowledgments SLY received support from the National Institute of Mental Health (K01MH098902). ACW acknowledges support from the National Institute of Environmental Health Sciences (R01 ES09137). SIM was supported by award number K01MH094246 from the National Institute of Mental Health. SDW acknowledges financial support from the National Institute of Mental Health (R01 MH-095683, R34 MH-094215) and the Burke Family Foundation. The content is solely the responsibility of the authors and does not necessarily represent the official views of the National Institute of Mental Health or the National Institutes of Health.

\section{References}

1. Sethi AK, Celentano DD, Gange SJ, Moore RD, Gallant JE. Association between adherence to antiretroviral therapy and human immunodeficiency virus drug resistance. Clin Infect Dis. 2003;37(8):1112-8.

2. Nachega JB, Hislop M, Dowdy DW, Chaisson RE, Regensberg L, Maartens G. Adherence to nonnucleoside reverse transcriptase inhibitor-based HIV therapy and virologic outcomes. Ann Intern Med. 2007;146(8):564-73.

3. Parienti JJ, Das-Douglas M, Massari V, et al. Not all missed doses are the same: sustained NNRTI treatment interruptions predict HIV rebound at low-to-moderate adherence levels. PLoS ONE. 2008;3(7):e2783.

4. Mills EJ, Nachega JB, Buchan I, et al. Adherence to antiretroviral therapy in sub-Saharan Africa and North America: a metaanalysis. JAMA. 2006;296(6):679-90.

5. Bangsberg DR, Perry S, Charlebois ED, et al. Non-adherence to highly active antiretroviral therapy predicts progression to AIDS. AIDS. 2001;15(9):1181-3.

6. Ford N, Kranzer K, Hilderbrand K, et al. Early initiation of antiretroviral therapy and associated reduction in mortality, morbidity and defaulting in a nurse-managed, community cohort in Lesotho. AIDS. 2010;24(17):2645-50.

7. Hermans S, van Leth F, Manabe Y, Hoepelman A, Lange J, Kambugu A. Earlier initiation of antiretroviral therapy, increased tuberculosis case finding and reduced mortality in a setting of improved HIV care: a retrospective cohort study. HIV Med. 2012;13(6):337-44.

8. Cohen MS, Chen YQ, McCauley M, et al. Prevention of HIV-1 infection with early antiretroviral therapy. $\mathrm{N}$ Engl $\mathrm{J}$ Med. 2011;365(6):493-505.

9. WHO. Antiretroviral drugs for treating pregnant women and preventing HIV infection in infants: recommendations for a public health approach. Geneva: WHO; 2010.

10. Food and Agriculture Organization of the United Nations. The State of Food Insecurity in the World, Rome; 2010.
11. Mugavero MJ, Norton WE, Saag MS. Health care system and policy factors influencing engagement in HIV medical care: piecing together the fragments of a fractured health care delivery system. Clin Infect Dis. 2011;52(Suppl 2):S238-46.

12. WHO. In: Sabaté E, editor. Adherence to long-term therapies: evidence for action. Geneva: WHO; 2003.

13. Andersen RM. Revisiting the behavioral model and access to medical care: does it matter? J Health Soc Behav. 1995;36(1): $1-10$.

14. Hardon A, Davey S, Gerrits T, et al. From access to adherence: the challenges of antiretroviral treatment-studies from Botswana, Tanzania and Uganda. Geneva: World Health Organization; 2006.

15. OhIarlaithe ea. Food insecurity is associated with suboptimal access, adherence, retention and treatment outcomes in HIV and TB care: understanding the linkages. AIDS Behav. 2012 (this issue).

16. Weiser SD, Young SL, Cohen CR, et al. Conceptual framework for understanding the bidirectional links between food insecurity and HIV/AIDS. Am J Clin Nutr. 2011;94(6):1729S-39S.

17. Coetzee B, Kagee A, Vermeulen N. Structural barriers to adherence to antiretroviral therapy in a resource-constrained setting: the perspectives of health care providers. AIDS Care. 2011;23(2):146-51.

18. Hardon AP, Akurut D, Comoro C, et al. Hunger, waiting time and transport costs: time to confront challenges to ART adherence in Africa. AIDS Care. 2007;19(5):658-65.

19. Unge C, Sodergard B, Marrone G, et al. Long-term adherence to antiretroviral treatment and program drop-out in a high-risk urban setting in sub-Saharan Africa: a prospective cohort study. PLoS ONE. 2010;5(10):e13613.

20. Duff P, Kipp W, Wild TC, Rubaale T, Okech-Ojony J. Barriers to accessing highly active antiretroviral therapy by HIV-positive women attending an antenatal clinic in a regional hospital in western Uganda. J Int AIDS Soc. 2010;13:37.

21. Weaver KE, Llabre MM, Duran RE, et al. A stress and coping model of medication adherence and viral load in HIV-positive men and women on highly active antiretroviral therapy (HAART). Health Psychol. 2005;24(4):385-92.

22. Holzemer WL, Corless IB, Nokes KM, et al. Predictors of selfreported adherence in persons living with HIV disease. AIDS Patient Care STDs. 1999;13(3):185-97.

23. Murray LK, Semrau K, McCurley E, et al. Barriers to acceptance and adherence of antiretroviral therapy in urban Zambian women: a qualitative study. AIDS Care. 2009;21(1):78-86.

24. Boyer S, Clerc I, Bonono CR, Marcellin F, Bile PC, Ventelou B. Non-adherence to antiretroviral treatment and unplanned treatment interruption among people living with HIV/AIDS in Cameroon: individual and healthcare supply-related factors. Soc Sci Med. 2011;72(8):1383-92.

25. Palepu A, Milloy MJ, Kerr T, Zhang R, Wood E. Homelessness and adherence to antiretroviral therapy among a cohort of HIVinfected injection drug users. J Urban Health. 2011;88(3): 545-55.

26. Nachega JB, Knowlton AR, Deluca A, et al. Treatment supporter to improve adherence to antiretroviral therapy in HIVinfected South African adults. A qualitative study. JAIDS. 2006; 43(Suppl 1):S127-33.

27. Howard AA, Arnsten JH, Lo Y, et al. A prospective study of adherence and viral load in a large multi-center cohort of HIVinfected women. AIDS. 2002;16(16):2175-82.

28. Nam SL, Fielding K, Avalos A, Dickinson D, Gaolathe T, Geissler PW. The relationship of acceptance or denial of HIVstatus to antiretroviral adherence among adult HIV patients in urban Botswana. Soc Sci Med. 2008;67(2):301-10.

29. Dahab M, Charalambous S, Hamilton R, et al. "That is why I stopped the ART": patients' \& providers' perspectives on 
barriers to and enablers of HIV treatment adherence in a South African workplace programme. BMC Public Health. 2008;8:63.

30. Watt MH, Maman S, Earp JA, et al. "It's all the time in my mind": facilitators of adherence to antiretroviral therapy in a Tanzanian setting. Soc Sci Med. 2009;68(10):1793-800.

31. Ware NC, Idoko J, Kaaya S, et al. Explaining adherence success in sub-Saharan Africa: an ethnographic study. PLoS Med. 2009;6(1):e11.

32. Remien RH, Hirky AE, Johnson MO, Weinhardt LS, Whittier D, Le GM. Adherence to medication treatment: a qualitative study of facilitators and barriers among a diverse sample of HIV + men and women in four US cities. AIDS Behav. 2003;7(1):61-72.

33. Mshana GH, Wamoyi J, Busza J, et al. Barriers to accessing antiretroviral therapy in Kisesa, Tanzania: a qualitative study of early rural referrals to the national program. AIDS Patient Care STDs. 2006;20(9):649-57.

34. Tuller DM, Bangsberg DR, Senkungu J, Ware NC, Emenyonu N, Weiser SD. Transportation costs impede sustained adherence and access to HAART in a clinic population in southwestern Uganda: a qualitative study. AIDS Behav. 2010;14(4): $778-84$.

35. Weiser S, Wolfe W, Bangsberg D, et al. Barriers to antiretroviral adherence for patients living with HIV infection and AIDS in Botswana. JAIDS. 2003;34(3):281-8.

36. Ammassari A, Murri R, Pezzotti P, et al. Self-reported symptoms and medication side effects influence adherence to highly active antiretroviral therapy in persons with HIV infection. JAIDS. 2001;28(5):445-9.

37. Stone VE, Hogan JW, Schuman P, et al. Antiretroviral regimen complexity, self-reported adherence, and HIV patients' understanding of their regimens: survey of women in the her study. JAIDS. 2001;28(2):124-31.

38. Nozaki I, Dube C, Kakimoto K, Yamada N, Simpungwe JB. Social factors affecting ART adherence in rural settings in Zambia. AIDS Care. 2011;23(7):831-8.

39. Anema A, Weiser SD, Fernandes KA, et al. High prevalence of food insecurity among HIV-infected individuals receiving HAART in a resource-rich setting. AIDS Care. 2011;23(2):221-30.

40. Peretti-Watel P, Spire B, Schiltz MA, et al. Vulnerability, unsafe sex and non-adherence to HAART: evidence from a large sample of French HIV/AIDS outpatients. Soc Sci Med. 2006; 62(10):2420-33.

41. Franke MF, Murray MB, Munoz M, et al. Food insufficiency is a risk factor for suboptimal antiretroviral therapy adherence among HIV-infected adults in urban Peru. AIDS Behav. 2011; 15(7):1483-9.

42. Kalichman SC, Cherry C, Amaral C, et al. Health and treatment implications of food insufficiency among people living with HIV/ AIDS, Atlanta, Georgia. J Urban Health. 2010;87(4):631-41.

43. Kidder DP, Wolitski RJ, Campsmith ML, Nakamura GV. Health status, health care use, medication use, and medication adherence among homeless and housed people living with HIV/AIDS. Am J Public Health. 2007;97(12):2238-45.

44. Crane JT, Kawuma A, Oyugi JH, et al. The price of adherence: qualitative findings from HIV positive individuals purchasing fixed-dose combination generic HIV antiretroviral therapy in Kampala, Uganda. AIDS Behav. 2006;10(4):437-42.

45. Kalichman SC, Grebler T. Stress and poverty predictors of treatment adherence among people with low-literacy living with HIV/AIDS. Psychosom Med. 2010;72(8):810-6.

46. Lambdin BH, Micek MA, Koepsell TD, et al. Patient volume, human resource levels, and attrition from HIV treatment programs in central Mozambique. JAIDS. 2011;57(3):e33-9.

47. Dlamini PS, Wantland D, Makoae LN, et al. HIV stigma and missed medications in HIV-positive people in five African countries. AIDS patient care and STDs. 2009;23(5):377-87.
48. Goudge J, Ngoma B. Exploring antiretroviral treatment adherence in an urban setting in South Africa. J Public Health Policy. 2011;32(Suppl 1):S52-64.

49. Pandit JA, Sirotin N, Tittle R, Onjolo E, Bukusi EA, Cohen CR. Shamba Maisha: a pilot study assessing impacts of a microirrigation intervention on the health and economic wellbeing of HIV patients. BMC Public Health. 2010;10:245.

50. Vreeman RC, Nyandiko WM, Sang E, Musick BS, Braitstein P, Wiehe SE. Impact of the Kenya post-election crisis on clinic attendance and medication adherence for HIV-infected children in western Kenya. Confl Health. 2009;3:5

51. Yoder RB, Nyandiko WM, Vreeman RC, et al. Long-term impact of the Kenya postelection crisis on clinic attendance and medication adherence for HIV-infected children in western Kenya. JAIDS. 2012;59(2):199-206.

52. Pyne-Mercier LD, John-Stewart GC, Richardson BA, et al. The consequences of post-election violence on antiretroviral HIV therapy in Kenya. AIDS Care. 2011;23(5):562-8.

53. Mills EJ, Nachega JB, Bangsberg DR, et al. Adherence to HAART: a systematic review of developed and developing nation patient-reported barriers and facilitators. PLoS Med. 2006;3(11):e438.

54. Chesney MA. Factors affecting adherence to antiretroviral therapy. Clin Infect Dis. 2000;30(Suppl 2):S171-6.

55. Azar MM, Springer SA, Meyer JP, Altice FL. A systematic review of the impact of alcohol use disorders on HIV treatment outcomes, adherence to antiretroviral therapy and health care utilization. Drug Alcohol Depend. 2010;112(3):178-93.

56. Merten S, Kenter E, McKenzie O, Musheke M, Ntalasha H, Martin-Hilber A. Patient-reported barriers and drivers of adherence to antiretrovirals in sub-Saharan Africa: a meta-ethnography. Trop Med Int Health. 2010;15(Suppl 1):16-33.

57. Castleman T, Seumo-Fosso E, Cogill B. Food and nutrition implications of antiretroviral therapy in resource limited settings. Washington, DC: Food and Nutrition Technical Assistance Project, Academy for Educational Development; 2004.

58. Houweling TA, Ronsmans C, Campbell OM, Kunst AE. Huge poor-rich inequalities in maternity care: an international comparative study of maternity and child care in developing countries. Bull World Health Organ. 2007;85(10):745-54.

59. World Bank. World development indicators. Washington, DC; 2010.

60. Braitstein P, Boulle A, Nash D, et al. Gender and the use of antiretroviral treatment in resource-constrained settings: findings from a multicenter collaboration. J Womens Health (Larchmt). 2008;17(1):47-55.

61. Falagas ME, Zarkadoulia EA, Pliatsika PA, Panos G. Socioeconomic status (SES) as a determinant of adherence to treatment in HIV infected patients: a systematic review of the literature. Retrovirology. 2008;5:13.

62. Rachlis BS, Mills EJ, Cole DC. Livelihood security and adherence to antiretroviral therapy in low and middle income settings: a systematic review. PLoS ONE. 2011;6(5):e18948.

63. Vreeman RC, Nyandiko WM, Ayaya SO, Walumbe EG, Marrero DG, Inui TS. Factors sustaining pediatric adherence to antiretroviral therapy in western Kenya. Qual Health Res. 2009;19(12):1716-29.

64. Haberer J, Mellins C. Pediatric adherence to HIV antiretroviral therapy. Curr HIV/AIDS Rep. 2009;6(4):194-200.

65. Bain-Brickley D, Butler LM, Kennedy GE, Rutherford GW. Interventions to improve adherence to antiretroviral therapy in children with HIV infection. Cochrane Database Syst Rev. 2011;(12):CD009513. doi:10.1002/14651858.CD009513.

66. Vreeman RC, Nyandiko WM, Ayaya SO, Walumbe EG, Marrero DG, Inui TS. The perceived impact of disclosure of pediatric HIV status on pediatric antiretroviral therapy adherence, 
child well-being, and social relationships in a resource-limited setting. AIDS Patient Care STDs. 2010;24(10):639-49.

67. Fetzer BC, Mupenda B, Lusiama J, Kitetele F, Golin C, Behets F. Barriers to and facilitators of adherence to pediatric antiretroviral therapy in a sub-Saharan setting: insights from a qualitative study. AIDS Patient Care STDs. 2011;25(10):611-21.

68. Singer M. Introduction to syndemics: a critical systems approach to public and community health. San Francisco: Jossey-Bass; 2009.

69. United Nations. United National General Assembly. Political Declaration on HIV/AIDS; 2006.

70. World Food Programme, World Health Organization, UNAIDS. HIV, food security, and nutrition. Policy Brief; 2008.

71. Weiser SD, Fernandes KA, Brandson EK, et al. The association between food insecurity and mortality among HIV-infected individuals on HAART. JAIDS. 2009;52(3):342-9.

72. Weiser SD, Leiter K, Bangsberg DR, et al. Food insufficiency is associated with high-risk sexual behavior among women in Botswana and Swaziland. PLoS Med. 2007;4(10):1589-97 discussion 1598.

73. Weiser SD, Frongillo EA, Ragland K, Hogg RS, Riley ED, Bangsberg DR. Food insecurity is associated with incomplete HIV RNA suppression among homeless and marginally housed HIV-infected individuals in San Francisco. J Gen Intern Med. 2009;24(1):14-20.

74. Wang EA, McGinnis KA, Fiellin DA, et al. Food insecurity is associated with poor virologic response among HIV-infected patients receiving antiretroviral medications. J Gen Intern Med. 2011;26(9):1012-8

75. McMahon JH, Wanke CA, Elliott JH, Skinner S, Tang AM. Repeated assessments of food security predict CD4 change in the setting of antiretroviral therapy. JAIDS. 2011;58(1):60-3.

76. Normen L, Chan K, Braitstein P, et al. Food insecurity and hunger are prevalent among HIV-positive individuals in British Columbia, Canada. J Nutr. 2005;135(4):820-5.

77. Weiser SD, Tsai AC, Gupta R, et al. Food insecurity is associated with morbidity and patterns of healthcare utilization among HIV-infected individuals in a resource-poor setting. AIDS. 2012;26(1):67-75.

78. Gillespie S, Kadiyala S. HIV/AIDS and food and nutrition security: from evidence to action. Washington, DC: International Food Policy Research Institute; 2005.

79. Weiser SD, Hatcher A, Frongillo EA, et al. Food insecurity is associated with greater acute care utilization among HIVinfected homeless and marginally housed individuals in San Francisco. J Gen Intern Med. 2012;28(1):91-8.

80. Weiser SD, Tuller DM, Frongillo EA, Senkungu J, Mukiibi N, Bangsberg DR. Food insecurity as a barrier to sustained antiretroviral therapy adherence in Uganda. PLoS ONE. 2010;5(4):e10340.

81. Nagata JM, Magerenge RO, Young SL, Oguta JO, Weiser SD, Cohen CR. Social determinants, lived experiences, and consequences of household food insecurity among persons living with HIV/AIDS on the shore of Lake Victoria, Kenya. AIDS Care. 2012;24(6):728-36

82. Curioso WH, Kepka D, Cabello R, Segura P, Kurth AE. Understanding the facilitators and barriers of antiretroviral adherence in Peru: a qualitative study. BMC Public Health. 2010;10:13.

83. Baldwin MR, Yori PP, Ford C, et al. Tuberculosis and nutrition: disease perceptions and health seeking behavior of household contacts in the Peruvian Amazon. Int $\mathrm{J}$ Tuberc Lung Dis. 2004;8(12):1484-91.

84. Senkomago V, Guwatudde D, Breda M, Khoshnood K. Barriers to antiretroviral adherence in $\mathrm{HIV}$-positive patients receiving free medication in Kayunga, Uganda. AIDS Care. 2011;23(10): 1246-53.

85. Au JT, Kayitenkore K, Shutes E, et al. Access to adequate nutrition is a major potential obstacle to antiretroviral adherence among HIV-infected individuals in Rwanda. AIDS. 2006;20 (16):2116-8.

86. Koethe JR, Blevins M, Bosire C, et al. Self-reported dietary intake and appetite predict early treatment outcome among lowBMI adults initiating HIV treatment in sub-Saharan Africa. Public Health Nutr. 2013;16(3):549-58.

87. Al-Harthi L, Voris J, Patterson BK, et al. Evaluation of the impact of highly active antiretroviral therapy on immune recovery in antiretroviral naive patients. HIV Med. 2004;5(1): $55-65$.

88. Keating SM, Golub ET, Nowicki M, et al. The effect of HIV infection and HAART on inflammatory biomarkers in a population-based cohort of women. AIDS. 2011;25(15):1823-32.

89. Groh K, Audet CM, Baptista A, et al. Barriers to antiretroviral therapy adherence in rural Mozambique. BMC Public Health. 2011;11:650.

90. Uzochukwu BS, Onwujekwe OE, Onoka AC, Okoli C, Uguru NP, Chukwuogo OI. Determinants of non-adherence to subsidized anti-retroviral treatment in southeast Nigeria. Health Policy Plan. 2009;24(3):189-96.

91. Riley ED, Moore K, Sorensen JL, Tulsky JP, Bangsberg DR, Neilands TB. Basic subsistence needs and overall health among human immunodeficiency virus-infected homeless and unstably housed women. Am J Epidemiol. 2011;174(5):515-22.

92. Characteristics associated with HIV infection among heterosexuals in urban areas with high AIDS prevalence-24 cities, United States, 2006-2007. MMWR. Morbidity and mortality weekly report. 2011;60(31):1045-1049.

93. Birbeck GL, Kvalsund MP, Byers PA, et al. Neuropsychiatric and socioeconomic status impact antiretroviral adherence and mortality in rural Zambia. Am J Trop Med Hyg. 2011;85(4): 782-9.

94. van Oosterhout JJ, Ndekha M, Moore E, Kumwenda JJ, Zijlstra EE, Manary M. The benefit of supplementary feeding for wasted Malawian adults initiating ART. AIDS Care. 2010;22(6): 737-42.

95. Cantrell RA, Sinkala M, Megazinni K, et al. A pilot study of food supplementation to improve adherence to antiretroviral therapy among food-insecure adults in Lusaka, Zambia. JAIDS. 2008;49(2):190-5.

96. Ivers LC, Chang Y, Gregory Jerome J, Freedberg KA. Food assistance is associated with improved body mass index, food security and attendance at clinic in an HIV program in central Haiti: a prospective observational cohort study. AIDS Res Ther. 2010;7:33.

97. Barnighausen T, Chaiyachati K, Chimbindi N, Peoples A, Haberer J, Newell ML. Interventions to increase antiretroviral adherence in sub-Saharan Africa: a systematic review of evaluation studies. Lancet Infect Dis. 2011;11(12):942-51.

98. Laraia BA, Siega-Riz AM, Gundersen C, Dole N. Psychosocial factors and socioeconomic indicators are associated with household food insecurity among pregnant women. J Nutr. 2006;136(1):177-82.

99. Sellen DW, Hadley C. Food insecurity and maternal-to-child transmission of HIV and AIDS in sub-Saharan Africa. Ann Anthropol Pract. 2011;35(1):28-49.

100. UNAIDS. 2008 Report on global AIDS epidemic; 2008.

101. Brewer DP, Catlett CS, Porter KN, et al. Physical limitations contribute to food insecurity and the food insecurity-obesity paradox in older adults at senior centers in Georgia. J Nutr Elder. 2010;29(2):150-69. 
102. WHO, UNAIDS, UNICEF. Towards universal access: scaling up priority HIV/AIDS interventions in the health sector. Progress report 2010: World Health Organisation; 2010.

103. WHO. Guidelines on co-trimoxazole prophylaxis for HIV-related infections among children, adolescents and adults in resource-limited settings: Recommendations for a public health approach. Geneva: WHO; 2006.

104. Zachariah R, Harries AD, Luo C, Bachman G, Graham SM. Scaling-up co-trimoxazole prophylaxis in HIV-exposed and HIV-infected children in high HIV-prevalence countries. Lancet Infect Dis. 2007;7(10):686-93.

105. Sturt AS, Dokubo EK, Sint TT. Antiretroviral therapy (ART) for treating HIV infection in ART-eligible pregnant women. Cochrane Database Syst Rev. 2010;(3):CD008440.

106. Kramer MS. The epidemiology of adverse pregnancy outcomes: an overview. J Nutr. 2003;133(5 Suppl 2):1592S-6S.

107. Villamor E, Saathoff E, Msamanga G, O'Brien ME, Manji K, Fawzi WW. Wasting during pregnancy increases the risk of mother-to-child HIV-1 transmission. JAIDS. 2005;38(5):622-6.

108. de Pee S, Semba RD. Role of nutrition in HIV infection: review of evidence for more effective programming in resource-limited settings. Food Nutr Bull. 2010;31(4):S313-44.

109. Young S, Muray K, Mwesigwa J, et al. Maternal nutritional status predicts adverse birth outcomes among HIV-infected rural Ugandan women receiving combination antiretroviral therapy. PloS One. 2012;7(8):e41934. doi:10.1371/journal.pone.0041934.

110. Food and Nutrition Technical Assistance Project. HIV/AIDS: a guide for nutritional care and support. Washington, DC: Academy for Educational Development; 2004.

111. Patil C, Abrams E, Steinmetz A, Young S. Appetite sensations and nausea and vomiting in pregnancy: an overview of the explanations. Ecol Food Nutr. 2012;51(5):394-417.

112. WHO, UNAIDS, UNFPA, UNICEF. Guidelines on HIV and infant feeding: World Health Organization; 2010.

113. Young SL, Mbuya MN, Chantry CJ, et al. Current knowledge and future research on infant feeding in the context of HIV: basic, clinical, behavioral, and programmatic perspectives. Adv Nutr. 2011;2(3):225-43.

114. Kerr RB, Berti PR, Chirwa M. Breastfeeding and mixed feeding practices in Malawi: timing, reasons, decision makers, and child health consequences. Food Nutr Bull. 2007;28(1):90-9.
115. Webb-Girard A, Cherobon A, Mbugua S, Kamau-Mbuthia E, Amin A, Sellen DW. Food insecurity is associated with attitudes towards exclusive breastfeeding among women in urban Kenya. Matern Child Nutr. 2012;8(2):199-214. doi:10.1111/j.1740-8709.2010. 00272.x.

116. Natamba B, Robine M, Luwedde F, et al. Breastfeeding practices and beliefs among HIV + pregnant and lactating women on antiretroviral therapy in rural Uganda indicate obstacles to following national guidelines. Paper presented at experimental biology, San Diego; 2012.

117. Skovdal M, Campbell C, Madanhire C, Nyamukapa C, Gregson $\mathrm{S}$. Challenges faced by elderly guardians in sustaining the adherence to antiretroviral therapy in HIV-infected children in Zimbabwe. AIDS Care. 2011;23(8):957-64.

118. Kundu CK, Samanta M, Sarkar M, Bhattacharyya S, Chatterjee S. Food supplementation as an incentive to improve pre-antiretroviral therapy clinic adherence in HIV-positive childrenexperience from Eastern India. J Trop Pediatr. 2012;58(1):31-7.

119. Tirivayi N, Groot W. Health and welfare effects of integrating AIDS treatment with food assistance in resource constrained settings: a systematic review of theory and evidence. Soc Sci Med. 2011;73(5):685-92.

120. Yager JE, Kadiyala S, Weiser SD. HIV/AIDS, food supplementation and livelihood programs in Uganda: a way forward? PLoS ONE. 2011;6(10):e26117.

121. Kadiyala S, Rawat R, Roopnaraine T, Babirye F, Ochai R. Applying a programme theory framework to improve livelihood interventions integrated with HIV care and treatment programmes. J Dev Effect. 2009;1:470-91.

122. The World Bank. Agriculture for Development. Washington, DC; 2007.

123. The World Bank. Gender in Agriculture Sourcebook. Washington, DC; 2009.

124. Reddi A, Powers MA, Thyssen A. HIV/AIDS and food insecurity: deadly syndemic or an opportunity for healthcare synergism in resource-limited settings of sub-Saharan Africa? AIDS. 2012;26:115-7. 